reduction' reactions at various temperatures and high gas speeds as met with in blast furnace operations. During the past few years the work, which is carried out by Dr. H. L. Saunders, has thrown such important new light on blast furnace reactions that recently the Federation decided to finance and develop parallel investigations upon actual blast furnace plant. With this end in view, a Committee has been formed, with Prof. Bone as chairman, to organise and carry out this programme of work.

\section{EleCtrochemistry}

Gaseous Combustion in Electric Discharges and Electrical Ignition. Inaugurated in 1925 by Asst. Prof. G. I. Finch, these investigations have been continuously prosecuted, and new light thrown on the combus. tion of hydrogen and carbon monoxide and on the part played by the hydroxyl radical in such circumstances.

In addition to having established the excitation view of electrical ignition, a notable improvement in the design of electrical ignition systems for mobile internal combustion engines hasbeenachieved.

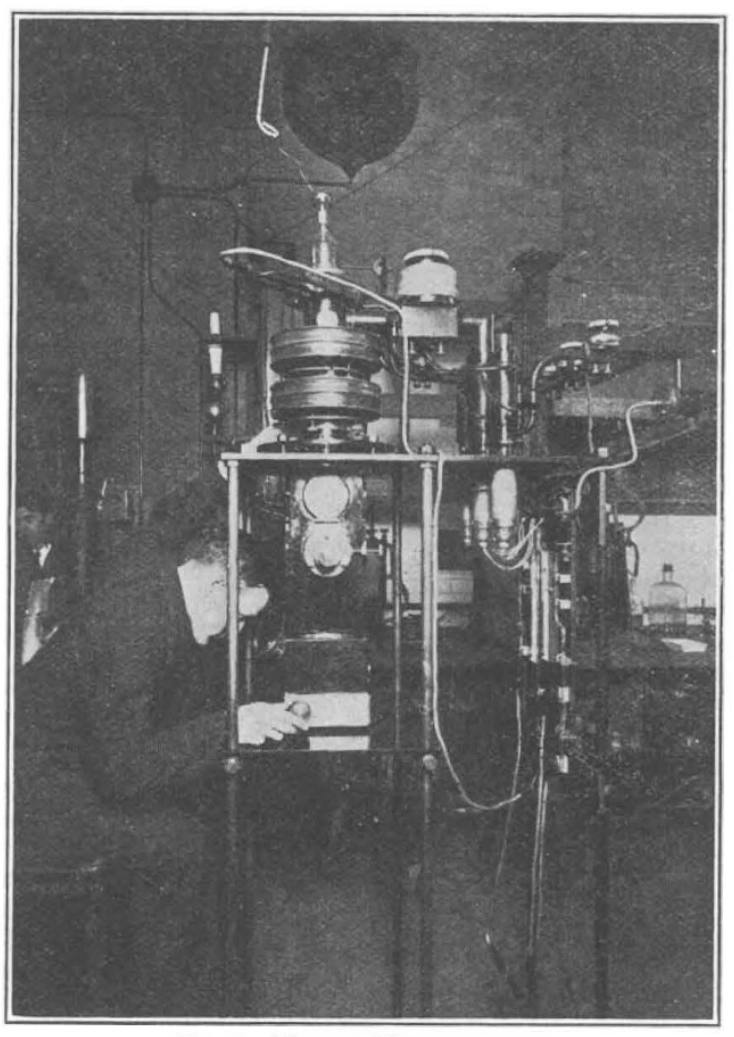

FIG. 1. Electron diffraction camera. has been established that electrical condition, catalytic activity and structure of surface catalysts are intimately related. Great progress in this field has recently been made possible by the application of the electron diffraction method of structure analysis.

A number of precision cameras designed by Prof. Finch were on view (Fig. 1) ; other chemical problems being attacked by this new method are: (i) corrosion, (ii) electrodeposition, (iii) thermionic and photo-electric emission, (iv) lubrication, (v) properties of colloidal metals, (vi) formation of surface compounds, etc.

Chemical Engineering

The chemical engineering section of the Depart ment suffered a severe loss through the death of Prof. J. W. Hinchley in 1931. Since that time, Asst. Prof. S. G. M. Ure has taken charge of it and is directing work on general problems such as : (i) heat transmission, (ii) flow of liquids through granular beds, woven materials, etc., (iii) the distribution of energy in ball mill operations, etc.

During the quinquen. Also as an outcome of work on the analysis of discharge phenomena in ignition, a type of high-speed cathode ray oscillograph has been developed which has now been widely adopted in other laboratories.

Electron Diffraction and Heterogeneous Catalysis. It

nium, 98 students, 21 of them from overseas, have passed through the Department; of 78 whose locations are known, 63 have passed into industry, 10 into research or business posts and 5 into academic work.

\title{
Lunar Influence on the East Anglian Herring Fishery
}

$\mathrm{F}^{\mathrm{L}}$ LUCTUATION in the yield from year to year, from month to month, and even from day to day, is one of the outstanding and disconcerting characteristies of all herring fisheries. For thirteen seasons, 1921-1933 inclusive, careful records have been kept of the amount of herrings landed daily at Yarmouth and Lowestoft during the late autumn (October-November) fishery off the East Anglian coast. These figures of daily landings have now been submitted to detailed analysis by the scientific staff of the Ministry of Agriculture and Fisheries, Lowestoft, who find that they reveal a definite monthly rhythm in the catches, the maxima coinciding with the period of full moon*.

When the moon is at full in the first week of October its effect is but slight, but the landings gradually increase as the season advances, to culminate in a peak during the week of November full

* Lunar Influence on the East Anglian Herring Fishery. By R. E. Savage and W. C. Hodgson. Journal du Conseil, 9, No. 2, 1934 ; pp. 223-239. moon. In these circumstances, it is only the middle and later parts of the season which produce good catches. A full moon occurring in the second week of October produces a pronounced peak in the curve of landings, this maximum being followed by one of approximately equal magnitude in the week of November full moon. Full moon in the third week of October produces a still more pronounced peak for this period, but the corresponding November full moon is considerably less effective. Finally, when the moon is at full during the fourth week of October, it produces the largest peak of all, but the late November moon is accompanied by a rise so slight as to be of little benefit to the fishery.

From these observations it follows that the best prospects for a successful fishery - at any rate from the point of view of production-are found when the October full moon occurs in the second week of the month. When this happens, the combined effects of the October and November moons are greatest, and a period of about five weeks good fishing may bo 
expected. A very late October full moon is the least promising of all, for then only one prominent peak occurs in the fishery. The period of good fishing is therefore very short, and if it should happen that the activities of the fishing fleet be restricted by adverse weather conditions at this time, the chances of a successful fishery in that season are extremely slight.

The occurrence of these peaks in the curves of landings during the weeks of full moon is held to be more than coincidence, and the data certainly appear adequately to support this view. The authors are at a loss, however, to suggest an explanation for this correlation between the yield of the East Anglian herring fishery and a phase of the moon. This task is made all the more difficult by the fact that the same correlation is not exhibited by the herring fisheries in other localities. Either there is no obvious correlation at all between the landings and the moon's phase-as in the Scottish fisheries-or the peaks occur during a different phase of the moonas at North Shields, where the maxima occur during the 'first quarter'.

It should be emphasised, however, that failure to find an explanation of the influence exerted by the moon on the great East Anglian fishery in no way detracts from the value of the observations which have demonstrated its existence. The authors are therefore to be congratulated upon having fully achieved the two-fold object of their investigations. In a notable advance towards the making of more accurate forecasts of fluctuations in the yield of an important fishery, they have succeeded also in adding materially to the sum of our knowledge concerning lunar periodicity in the behaviour of animals.

G. A. S.

\section{University and Educational Intelligence}

CAMBRIDGE.-The Vice-Chancellor announces a further gift from Dr. G. P. Bidder, of Trinity College, for the benefit of occupants of the Cambridge table at the Zoological Station in Naples. For three years Dr. Bidder has made annual payments of 5,000 lire into a Naples bank for the maintenance of occupants of the table during their sojourn in Naples. He now offers to deposit in that bank securities which, by the use of principal and interest, will provide 5,000 lire annually for the same purpose, for a further period of ten years. The professor of zoology will have discretionary powers over the fund.

The Goldsmiths' Company has made a grant of $£ 5,500$ for defraying the expenses of an investigation of the alloys of silver, to be carried out in the Metallurgy Laboratory under the guidance of Prof. R. S. Hutton, professor of metallurgy at Cambridge. The grant is to be spread over three years.

An American "Educational Review" published as a supplement to School and Society of December I conveys the impression that school teachers in the United States are to-day very much on the defensive. Awakening from a dream of heaven-ordained security, they recognise that they have lost much of the unquestioning popular reverence they and their predecessors enjoyed for generations, and are no longer taken seriously as oracles of civic wisdom. If the President's 'new deal' is to provide old-age pensions and unemployment insurance, there will, it is felt, be a danger of these social services being financed in part by encroaching on school budgets. The same review comments on the progress of adult education with special reference to an 'alumni education' movement which is peculiar to America. Among its manifestations are mentioned a three-day conference at Seattle on present-day economic and political problems, in which a thousand alumni of the University of Washington participated, similar conferences of alumni of other universities and an annual two-week Institute of Public Affairs organised by the University of Virginia.

\section{Science News a Century Ago}

\section{The Entomological Society}

The anniversary meeting of the Entomological Society was held on January 26, 1835, J. G. Children, Sec. R.S., the president, being in the chair. After the passing of the minutes and accounts, the president delivered an address in the course of which he congratulated the Society on the progress of entomology and the favourable report which had just been read, while the secretary followed with a sketch of the progress of the science at home and abroad. The officers elected for 1835 were: President, Rev. F. W. Hope ; Treasurer, Mr. Yarrell; Curator, Mr. Pickering; and Secretary, Mr. Westwood.

\section{Royal College of Physicians}

The president of the Royal College of Physicians from 1820 until 1844 was Sir Henry Halford (17661844), who was physician in turn to George IV, William IV and Queen Victoria. On January 26, 1835, according to The Times, the evening meetings of the Society were commenced at the College in Pall Mall. Sir Henry Halford was in the chair and the meeting was attended by about seven hundred persons including many distinguished statesmen, lawyers and others. The meeting began at 9 o'clock and the company dispersed at 11 o'clock. The president, said The Times, read a very interesting paper containing some observations on the treatment adopted by medical men from a very early period, in the care of various complaints, and related many amusing anecdotes of the remedies they applied. He described the different complaints which terminated the lives of the monarchs who governed Great Britain, and also explained the circumstances attending the deaths of Addison, Dryden, Dean Swift and other distinguished characters.

\section{Steam Navigation upon the Danube}

Under the above heading, the Athenaeum on January 31, 1835, said : "Very gratifying accounts have recently been received of the progress of steam navigation upon this noble river. Under the auspices of the Austrian government, the whole region from Presburg to the Black Sea, and even to Constantinople, a distance of fifteen hundred miles, has lately been opened to the influence of steam. This project was first undertaken by Count Czechengi, a Hungarian nobleman of great fortune and very enlightened mind, who in quest of mechanical information, has made several journies to this country. Unlike the majority of the Hungarian nobles the Count has exhibited the most enthusiastic devotion to the improvement of his country, by the introduction of the useful arts, and his operations for improving the navigation of the Danube have been upon a scale so vast, as to entitle him to the appellation of the Bridgewater of the German States. ..." 